\title{
Detección de Fusarium semitectum en vainas de plantas de Moringa (Moringa oleifera Lam)
}

\author{
(Detection of Fusarium semitectum from pods of Moringa plants (Moringa \\ oleifera Lam)
}

Daymara I Vaillant $\mathbf{F}^{1 *}$, Yamilka Pérez B $\mathbf{B}^{\mathbf{1}}$, Rebeca Ramírez $\mathbf{O}^{\mathbf{1}}$
${ }^{1}$ Instituto de Investigaciones de Sanidad Vegetal (INISAV).
V110 \#214 / 5ta B y 5ta F, Miramar, Playa. La Habana, Cuba.
Código Postal 11600. Tel: 202-2517-19 ext 149.
*Autor para correspondencia: dvaillant@inisav.cu

RECIBIDO: 20 de Julio de 2015

APROBADO: 25 de Septiembre de 2015

LOS AUTORES DECLARAN NO TENER CONFLICTO DE INTERESES

Palabras claves: Enfermedades fúngicas, Fusarium semitectum, Moringa.

Key words: Fungi disease, Fusarium semitectum, Moringa.

\begin{abstract}
RESUMEN
Se analizaron muestras de Moringa oleifera procedentes de la provincia Habana, Cuba con el objetivo de determinar el agente causal de los daños. Las plantas presentaban afectaciones en las vainas, tallo y follaje iniciadas por insecto seguida por síntomas típicos de hongos fitopatógenos. Las muestras fueron procesadas y se determinó que el agente causal es el hongo fitopatógeno Fusarium semitectum. Este hongo se asocia a Fusicladium sp causando daños severos en la planta. En Cuba se ha aislado fundamentalmente en lotes de semillas de moringa.
\end{abstract}

\begin{abstract}
It analyzed samples of Moringa oleifera from Habana province, Cuba with the objective of to determinate the causal agent of the damages. The plants shows affectations in pods, stems and foliage initiated for insect straight on typical symp-
\end{abstract}

toms of phytopathongens fungi. The samples were preprocessed and it determined that causal agent is phytopathongens fungus Fusarium semitectum. This fungus is associated to Fusicladium sp caused severe damages in the plant. In Cuba it has isolated principally from fractions of moringa seeds.

\section{INTRODUCCIÓN}

La planta de Moringa oleifera posee cualidades nutricionales sobresalientes y está considerada como uno de los mejores vegetales perennes. Todas las partes de la planta son comestibles. El contenido de proteínas, vitaminas y minerales es sobresaliente (Doerr y Williams, 2009). Esta planta tiene propiedades medicinales, por lo que es usada en muchos países como remedio para varias enfermedades; además que se emplea como alimento animal (Pérez, 2010). En Cuba la Moringa crece de forma silvestre en todo lo largo del país, pero en la actualidad se ha comenzado la introducción del cultivo de esta planta con fines producti- 
vos. En el año 2012 en plantaciones de moringa en la provincia La Habana, se comenzaron a observar afectaciones en las vainas, tallo y follaje, las plantas mostraban daños por insecto en las vainas, seguido de manchas pardas de una podredumbre típica de afectaciones por hongos (figura 1). Se tomaron muestras de vainas con sintomatología con el objetivo de determinar el agente causal de la enfermedad.

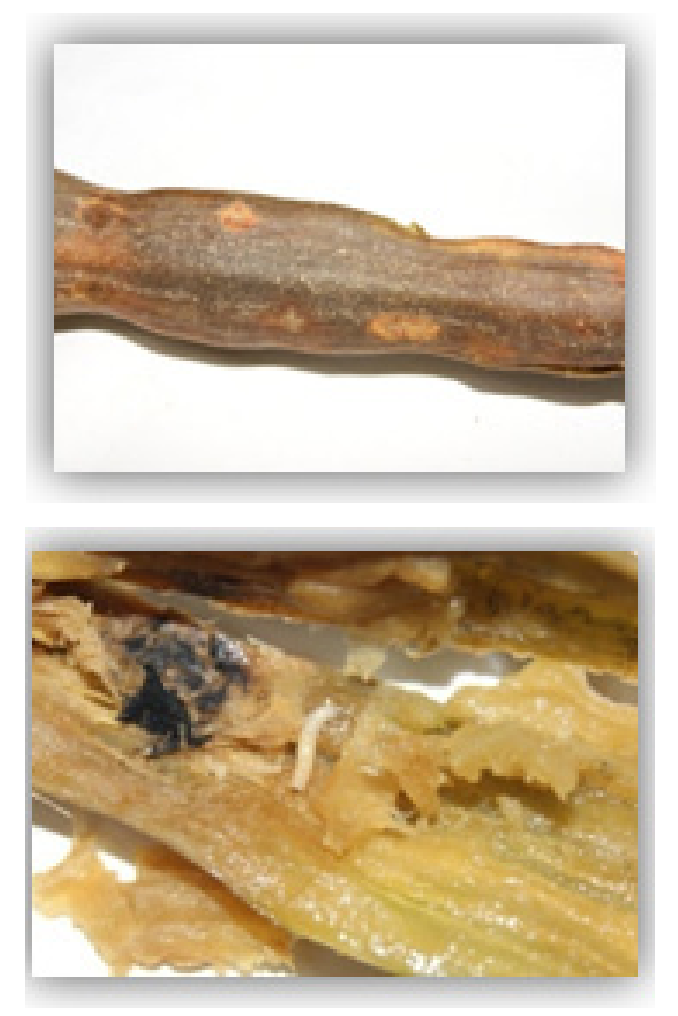

Figura 1. Síntomas en vainas de moringa.

\section{MATERIALES Y MÉTODO}

Las muestras de vainas fueron lavadas con abundante agua corriente y cortada en pequeños fragmentos; los cuales fueron desinfectados con hipoclorito de sodio al $1 \%$ durante tres minutos y lavados en agua destilada estéril. Luego se realizaron en condiciones de asepsia, pequeños cortes los cuales se sembraron en agar-agua y se incubaron a $25 \mathrm{C}^{\circ}$. Una vez que hubo crecimiento micelial, las colonias fueron transferidas a tubos con agar papa dextrosa (PDA). Los cuales se incubaron a las mismas condiciones.

\section{RESULTADOS Y DISCUSIÓN}

Transcurrido el tiempo de incubación se hicieron observaciones al microscopio óptico de cada colonia crecida y se determinó mediantes claves y descripciones taxonómicas que el agente causal era Fusarium semitectum (Leslie and Summerell, 2006). El patógeno se caracterizó por presentar una coloración salmón en medio PDA, con un micelio de tipo algodonoso. En medio SNA (Spezieller Nährstoffarmer Agar) no formó esporodoquios. Las células conidiógenas eran monolocales y multiocales. El hongo desarrolló macroconidios y no se observaron microconidios. Los macroconidios presentaban de 3 a 5 septos de forma curva hacia la base, algo pedicelados. Los conidios median de 10 a 45 x 3 a 5,3 ųm.

Gui-zhi et al. 2006 detectaron Fusarium semitectum asociado a Fusicladium sp en plantas de Moringa con afectaciones fundamentalmente en raíces, provocando la pérdida de follaje, además de pudrición en las vainas, muy similar a los síntomas observados en las muestras analizadas. Por otra parte Martínez et al. 2013 realizaron un análisis micológico de semillas de moringa y en el estudio determinaron a $F$. semitectum con una frecuencia de 52,8\%. La literatura describe a este fitopatógeno relacionado con el deterioro de semillas, fundamentalmente en soya (Ferri et al. 2005).

\section{AGRADECIMIENTOS}

Queremos agradecerle al Lic. Rudy de la Masa por facilitar las fotografías de las vainas de moringa con la sintomatología. 


\section{REFERENCIAS}

1. Doerr, E and Williams, N. 2008. Moringa Manual. En: Hhtp://www pctanzania.or. Última consulta: noviembre, 2013.

2. Ferri, M.; Pioli, R.; Magra, G. 2005. Evaluación de sintomatologías de semillas de soja asociadas a enfermedades fúngicas de fin de ciclo. Revista Agromensaje (7). En: Hhtp://wwwrephip.unr. edu.ar. Última consulta: enero, 2015.

3. Gui-zhi, J.; Hong-chang, A.; Chang-fen, L. 2006. Main Diseases and Pests on Moringa Trees in Xishaungbanna. Journal of Changjiang Vegetables. 2008-07.
4. Leslie, J and Summerll, B.A. 2006. The Fusarium laboratory manual. Blackwell Publishing. First edition. 248-250 pp. Manhata, USA.

5. Martínez, E.; Cantillo, T.; García, D. 2013. Micobiota asociada a lotes importados de semillas de moringa (Moringa olifera). Fitosanidad 17(3): 125-129.

6. Pérez, A.; Sánchez, T.; Armengol, N.; Reyes, F. 2010. Características y potencialidades de $\mathrm{Mo}$ ringa oleifera, Lamark. Una alternativa para la alimentación animal. Pastos y Forrajes 33 (4): 1-16. 